\title{
Low expression VEGF haplotype increases the risk for tetralogy of Fallot: a family based association study
}

\author{
D Lambrechts, K Devriendt, D A Driscoll, E Goldmuntz, M Gewillig, R Vlietinck, D Collen, \\ P Carmeliet
}

J Med Genet 2005;42:519-522. doi: 10.1136/img.2004.026443

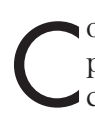
ongenital heart disease (CHD) presents a huge medical problem, as it affects between two and eight newborn children per 100 live births. ${ }^{1}$ Risk factors include alcohol and drug consumption as well as genetic defects. However, chromosomal and single gene defects cause only a relatively minor proportion of cases and, thus, most CHD is considered to be multi-factorial in origin, with various genes interacting with each other or with environmental factors to determine disease liability. ${ }^{2}$ To date, none of the CHD genetic susceptibility factors have been discovered.

Tetralogy of Fallot (TOF) is a common form of CHD, characterised by a subaortic ventricular septum defect (VSD), an overriding aorta, a right ventricular outflow tract obstruction, and right ventricular hypertrophy. TOF occurs in 4.21 of every 10000 births and is the most common type of CHD with cyanosis after 1 year of life. ${ }^{1}$ TOF may occur as part of the DiGeorge syndrome (DGS) which is caused by deletions of chromosome $22 q 11$ and characterised by conotruncal cardiac, craniofacial, thymic, and parathyroid anomalies. However, in most cases (in 2.65 per 10000 children) TOF occurs as an isolated defect. Mutations in the JAGGEDI or NKX2.5 genes have been found in only a few percentages of cases with isolated, non-syndromic TOF and thus, the genetic etiology in the large majority of these cases remains entirely unknown. ${ }^{2}$ By using a multi-genetic approach, we recently discovered that $V E G F$ is a modifier of DGS. ${ }^{3}$ We therefore assessed here whether VEGF might be a modifier of the cardiac birth defects in subjects with isolated, non-syndromic TOF.

\section{METHODS}

\section{Study design and participants}

To examine whether $V E G F$ gene variations are associated with TOF, we used the transmission disequilibrium test (TDT) to analyse linkage disequilibrium of single nucleotide polymorphisms (SNPs) in the VEGF gene in trios of parents and their proband affected with TOF. A total of 148 probands (84 males, 64 females; 73 Caucasians, 58 Caucasians of Flemish origin, four Afro-Americans, two Hispanics, and 11 trios of unknown or mixed ethnic origin) and their parents were studied. Ninety trios were recruited by the Children's Hospital in Philadelphia, USA, and 58 trios by the University Hospital in Leuven, Belgium. Criteria for diagnosis of TOF included the presence of a subaortic VSD, an overriding aorta, a right ventricular outflow tract obstruction (infundibular, valvar, supravalvar, or a combination), and right ventricular hypertrophy. Subjects with a 22 q11 deletion were excluded from the analysis. To determine whether the association was specific for TOF, we also studied probands with transposition of the great arteries (TGA). A total of 40 probands (27 males and 13 females; 29 Caucasians, one Asian, one Hispanic, three Afro-Americans, and six of mixed or unknown ethnic origin) and their parents were recruited at the Children's Hospital, Philadelphia. Thirty seven patients were diagnosed

\section{Key points}

- Tetralogy of Fallot (TOF), one of the most common forms of congenital heart disease, occurs as part of the DiGeorge syndrome (DGS). However, in most cases, TOF is not caused by chromosomal or single gene defects, but presumably results from genetic variations of several susceptibility factors.

- Here, we report that common polymorphisms in the VEGF promoter $(-2578 \mathrm{~A},-1154 \mathrm{~A})$ and leader sequence (-634G), known to lower vascular endothelial growth factor (VEGF) levels, increase the risk for TOF. Genotyping of 148 families with isolated, nonsyndromic TOF revealed that the low-VEGF haplotype $-2578 \mathrm{~A} /-1154 \mathrm{~A} /-634 \mathrm{G}$ (AAG) was overtransmitted to affected children $(p=0.008)$. Moreover, meta-analysis of patients with isolated, non-syndromic TOF and DGS patients with TOF revealed that the AAG haplotype increased the risk for TOF 1.8-fold ( $p=0.0008)$.

- VEGF is the first modifier gene identified for TOF.

with a D-TGA, which is the more common form of TGA and consists of a complete inversion of the great vessels, so that the aorta arises from the right ventricle and the pulmonary artery from the left ventricle, while three patients were diagnosed with an L-TGA, in which the ventricles are inverted. The study was approved by the Institutional Review Board for the Protection of Human Subjects and the Research Ethics Board in Philadelphia and Leuven, respectively, and written informed consent to participate in the study was obtained from all subjects or their legal representatives.

\section{SNP genotyping}

Three SNPs in the VEGF gene regulatory regions were studied: the first two SNPs $(-2578 \mathrm{C} / \mathrm{A}$ and $-1154 \mathrm{G} / \mathrm{A}$; positions relative to the $V E G F$ translation start site) are located in the VEGF promoter and the third SNP $(-634 \mathrm{G} / \mathrm{C})$ is located in the VEGF leader sequence. Characterisation of the $V E G F$ genotypes was performed by TaqMan minor groove binding probes and real time allelic discrimination of $V E G F$ SNPs. The following forward and reverse primers were used for the $-1154 \mathrm{G} / \mathrm{A}$ SNP: 5'-CCGCTACCAGCCGACTTTT-3' and

Abbreviations: CHD, congenital heart disease; DGS, DiGeorge syndrome; SNP, single nucleotide polymorphism; TDT, transmission disequilibrium test; TGA, transposition of the great arteries; TOF, tetralogy of Fallot; VEGF, vascular endothelial growth factor; VSD, ventricular septum defect 
Table 1 Transmission of VEGF alleles from heterozygous parents to TOF affected children

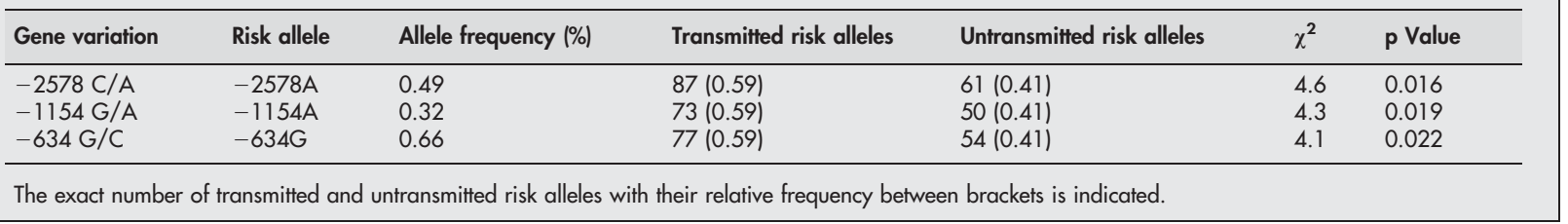

5'-TGGGTAATTTTCAGGCTGTGAAC-3'; and for the -634G/C SNP: 5'-CAGAGACAAGTCGAGGAAGAGAGAGA-3' and 5'CCCCAAAAGCAGGTCACTCA-3'. The following labelled probes were used for the $-1154 \mathrm{G} / \mathrm{A}$ SNP: $5^{\prime}$-CCTCAGCCCT TCC-VIC-3' and 5'-CCTCAGCCCCTCC-FAM-3'; and for the -634G/C SNP: 5'-CTGTCGCTTTCGCTGCTGCTCGCA-FAM-3'

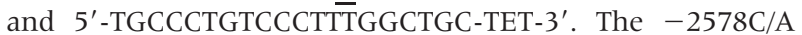
SNP was genotyped by pyrosequencing as described previously. ${ }^{4}$

\section{Statistical analysis}

The GeneHunter transmission disequilibrium command command was used to calculate the non-parametric linkage statistic for the VEGF alleles and haplotypes. ${ }^{5}$ Because previously obtained biological data suggested which low$V E G F$ alleles or haplotypes might increase the risk for TOF, we knew in advance the direction of the test. ${ }^{3}$ We therefore calculated one sided $\mathrm{p}$ values by halving the two sided probabilities generated by GeneHunter for the AAG haplotype and for the $V E G F$ alleles in the direction of their appearance in the AAG haplotype. For the meta-analysis, we compared the number of AAG haplotypes in cases and controls from the DGS study (replication study) and calculated the crude odds ratio and $95 \%$ confidence interval (CI) by $\chi^{2}$ analysis with 1 degree of freedom. ${ }^{3}$ The odds ratio for the TDT study (present study) was calculated by treating the number of transmissions of the AAG haplotype as the number of occurrences of that haplotype in cases and considering the controls to be a very large population with equal numbers of the haplotype (to reflect the expected 50:50 transmission ratio). ${ }^{6}$ As both studies measure a different true effect (that is, the risk in non-syndromic TOF or syndromic TOF), we calculated the average effect or pooled odds ratio for the AAG haplotype under a random effects model. ${ }^{7}$ To take into account the possibility of heterogeneity across both studies, a statistical test for heterogeneity was performed based on the Q statistic, for which a $\mathrm{p}$ value $<0.05$ indicates a lack of heterogeneity.

\section{RESULTS}

We previously established that the $-2578 \mathrm{~A}$ and $-1154 \mathrm{~A}$ alleles, which are located in the VEGF promoter, lower VEGF gene transcription, while the $-634 \mathrm{G}$ allele, which is located in the VEGF 5'UTR, reduces internal ribosome entry site mediated $V E G F$ expression and translation of the large LVEGF isoform. ${ }^{4}$ Genotyping of the VEGF SNPs in trios of parents and their proband affected with TOF revealed that the $-2578 \mathrm{~A},-1154 \mathrm{~A}$, and $-634 \mathrm{G}$ alleles were transmitted to patients with TOF more frequently than expected by mendelian inheritance, that is in 59\% of all transmissions (table 1). Thus, alleles associated with low levels of VEGF were significantly overtransmitted towards patients with TOF. In European populations, the $-2578,-1154$, and -634 $V E G F$ SNPs are in linkage disequilibrium and only four $V E G F$ haplotypes are commonly observed, that is AAG, AGG, CGG, and CGC (each letter refers to the SNP of the $-2578,-1154$, and -634 allele, respectively; see table 2 for more explanation). ${ }^{4}$ Despite the genetic heterogeneity of the American population, the same four haplotypes (that is, AAG, AGG, CGG, and CGC) present in European populations also predominated in the American population. ${ }^{4}$ Haplotypes could therefore be converted into genotypes and the parent to offspring transmission of haplotypes unambiguously determined for all families. The AAG haplotype, which lowers VEGF expression, ${ }^{4}$ was transmitted in $61 \%$ of all transmissions ( $p=0.008$; table 2 ). The AGG and CGG haplotypes were not significantly overtransmitted to affected children, though there was a tendency for the AGG haplotype to be overtransmitted (table 2).

To further assess whether the association of VEGF with isolated, non-syndromic TOF was not false-positive, we performed a meta-analysis by calculating the pooled odds ratio for the association of the common AAG haplotype with isolated, non-syndromic forms of TOF (present study) and with TOF associated with DGS (replication study ${ }^{3}$ ). By metaanalysis, the AAG haplotype was found to increase the risk 1.8-fold under a random effect model $(\mathrm{CI}=1.3$ to 2.5; $\mathrm{p}=0.0008$; test of homogeneity Cochran $\mathrm{Q}, \mathrm{p}=0.15)$. Thus, the low-VEGF AAG haplotype conferred an increased risk for TOF, both when occurring as an isolated, non-syndromic defect as well as in the context of DGS.

To determine whether this association was specific for TOF, we also studied probands with TGA and their parents. None of the VEGF alleles or haplotypes were transmitted significantly more often than expected by normal mendelian inheritance (table 3 ). This suggests that the association between the low-VEGF alleles and TOF was specific and that low-VEGF alleles do not simply predispose to CHD. A negligible role for VEGF in TGA may not be surprising, as this lesion does not belong to the typical spectrum of conotruncal defects in DGS patients and mouse models. ${ }^{9-11}$ In addition, there is little evidence for a genetic predisposition for TGA, as only very few familial cases have been reported to date $^{12}$ and a recent study even failed to identify any recurrence among offspring of adults with TGA. ${ }^{2}$

Table 2 Transmission of VEGF haplotypes from heterozygous parents to TOF affected children

\begin{tabular}{llllll}
\hline Haplotype & Haplotype frequency $(\%)$ & Transmitted haplotypes & Untransmitted haplotypes & $\chi^{2}$ & $p$ Value \\
\hline AAG & 0.33 & $72(0.61)$ & $46(0.39)$ & 5.8 & 0.008 \\
AGG & 0.17 & $44(0.55)$ & $36(0.45)$ & 0.8 & 0.19 \\
CGC & 0.33 & $52(0.41)$ & $74(0.59)$ & 3.2 & 0.04 \\
CGG & 0.17 & $43(0.47)$ & $49(0.53)$ & 0.4 & 0.53 \\
\hline
\end{tabular}

The VEGF haplotypes and their frequencies are presented. The exact number of transmitted and untransmitted haplotypes with their relative frequency between brackets is indicated. AAG: $-2578 \mathrm{~A} /-1154 \mathrm{~A} /-634 \mathrm{G}$ haplotype; AGG: $-2578 \mathrm{~A} /-1154 \mathrm{G} /-634 \mathrm{G}$ haplotype; CGC: $-2578 \mathrm{C} /-1154 \mathrm{G} /-634 \mathrm{C}$ haplotype; CGG: $-2578 \mathrm{C} /-1154 \mathrm{G} /-634 \mathrm{G}$ haplotype. 
Table 3 Transmission of VEGF alleles from heterozygous parents to TGA affected children

\begin{tabular}{lllllll}
\hline Gene variation & Risk allele & Allele frequency (\%) & Transmitted risk alleles & Untransmitted risk alleles & $\chi^{2}$ & $\mathrm{p}$ Value \\
\hline$-2578 \mathrm{C} / \mathrm{A}$ & $-2578 \mathrm{~A}$ & 0.48 & $18(0.53)$ & $16(0.47)$ & 0.1 & 0.73 \\
$-1154 \mathrm{G} / \mathrm{A}$ & $-1154 \mathrm{~A}$ & 0.34 & $16(0.48)$ & $17(0.52)$ & 0.03 & 0.86 \\
$-634 \mathrm{G} / \mathrm{C}$ & $-634 \mathrm{G}$ & 0.73 & $16(0.55)$ & $13(0.45)$ & 0.3 & 0.58 \\
\hline
\end{tabular}

The exact number of transmitted and untransmitted risk alleles with their relative frequency between brackets is indicated. Two sided $p$ values are presented.

\section{DISCUSSION}

Both environmental and genetic risk factors are generally considered to contribute to CHD. However, single gene defects, such as mutations in TBXI, TBX5, GATA4, and $N K X 2.5$, explain only very few CHD cases $(<1-4 \%)$ and, even then, their clinical spectrum is often quite variable. ${ }^{13-15}$ It has, therefore, often been hypothesised, but never proven, that susceptibility to and the expressivity of most cases of CHD is in fact caused by genetic variations and several interacting susceptibility factors. ${ }^{12}{ }^{16} 17$ The most significant finding of this study is that VEGF may well be such a modifier gene for TOF. Indeed, a low-VEGF haplotype (AAG), commonly occurring in up to a third of European and American populations, increased the risk for the development of an isolated, non-syndromic form as well as a syndromic form of TOF. To the best of our knowledge, this is the first evidence for an association between a modifier gene and any type of CHD.

How does VEGF modify the clinical spectrum of CHD and, in particular, of TOF? In mice Vegf expression in the developing heart occurs in a highly specific spatio-temporal pattern. At the onset of chamber septation, Vegf is up regulated in two diametrically opposed regions of the myocardium, which precisely mark the sites of atrioventricular canal formation. ${ }^{18}{ }^{19}$ Vegf expression hotspots are also present in the fourth and sixth pharyngeal arches, preceding remodelling of the corresponding arch arteries. ${ }^{3}$ Thus, VEGF is expressed at sites known to play a critical role in the formation of the atrioventricular canal and the remodelling of the large thoracic arteries. That VEGF is also functionally involved and that VEGF levels must be tightly regulated in cardiac morphogenesis is evidenced by various genetic mouse models. For instance, lack of even a single Vegf allele disregulates embryonic heart formation, ${ }^{20}{ }^{21}$ while newborn mice lacking the most critical Vegf ${ }^{164}$ isoform die of DGS-like cardiac birth defects-several of them due to TOF. ${ }^{3}$ All these findings thus indicate that precise control of $V E G F$ expression is required for cardiac morphogenesis, even though the downstream pathways of VEGF involved in this process remain to be elucidated. VEGF was once considered to be the most endothelial cell-specific growth factor, but numerous studies now indicate that this growth factor also affects neural, epithelial, and mesenchymal cells. ${ }^{22}{ }^{23}$ Whether VEGF thus affects neural crest cells, epithelial arch endoderm cells, or other cell types involved in cardiac morphogenesis is an outstanding but intriguing question. Whatever the mechanism, the role of VEGF must be specific, as this growth factor is not associated with the transposition of the great arteries.

In conclusion, the present human genetic evidence that the AAG haplotype of the VEGF gene increases the risk for DGS associated and non-syndromic TOF, together with our previous functional in vivo data in genetic mouse and zebra fish models and with the in vitro findings that the "at risk" AAG haplotype lowers VEGF expression, ${ }^{4}$ suggests that $V E G F$ is indeed a modifier of TOF.

\section{ACKNOWLEDGEMENTS}

We thank the patients and their families who consented to this study. The authors thank A Claeys and S Jansen for technical support.

\section{Authors' affiliations}

P Carmeliet, D Lambrechts, D Collen, The Center for Transgene Technology and Gene Therapy, Flanders Interuniversity Institute for Biotechnology, Leuven, Belgium

R Vlietinck, Division of Population Genetics and Bioinformatics, University of Maastricht, The Netherlands

K Devriendt, M Gewillig, The Center for Human Genetics and Department of Pediatrics, Katholieke Universiteit Leuven, Leuven, Belgium

D A Driscoll, Division of Human Genetics and Molecular Biology, University of Pennsylvania School of Medicine, Philadelphia, PA, USA E Goldmuntz, Division of Pediatric Cardiology, Department of Pediatrics, University of Pennsylvania School of Medicine, Philadelphia, PA, USA

$D L$ is a post doctoral fellow supported by the Fund for Scientific Research-Flanders (FWO, Belgium). PC is supported in part by the European Union (Biomed BMH4 CT98 3380), by grant \#G0125.00 from the FWO, Belgium, by an unrestricted Bristol-Myers-Squibb grant, by grant \#GOA2001/09 from the Concerted Research Activities, Belgium, and by grant \#IAP-P5/02 from the Belgian Science Policy. KD is a senior clinical investigator of the FWO and is supported by grants from the Interuniversity Attraction Poles and the Belgian Foundation for Research in Paediatric Cardiology. This study was further supported by the National Institute of Health grant P5O HL62177 to DAD and EG, and by the Nutrition and Toxicology and Growth and Development Research Institutes in Maastricht to RV.

\section{Competing interests: none declared}

Ethics approval: The study was approved by the Institutional Review Board for the Protection of Human Subjects and the Research Ethics Board in Philadelphia and Leuven, respectively, and written informed consent to participate in the study was obtained from all subjects or their legal representatives.

Correspondence to: Professor Peter Carmeliet, The Center for Transgene Technology and Gene Therapy, Flanders Interuniversity Institute for Biotechnology, KULeuven, Herestraat 49, Leuven, B-3000, Belgium; peter.carmelieł@med.kuleuven.ac.be

Received 13 August 2004

Revised version received 19 October 2004

\section{REFERENCES}

1 Hoffman JI, Kaplan S, Liberthson RR. Prevalence of congenital heart disease. Am Heart J 2004; 147(3):425-39.

2 Burn J, Brennan P, Little J, Holloway S, Coffey R, Somerville J, Dennis NR, Allan L, Arnold R, Deanfield JE, Godman M, Houston A, Keeton B, Oakley C, Scott O, Silove E, Wilkinson J, Pembrey M, Hunter AS. Recurrence risks in offspring of adults with major heart defects: results from first cohort of British collaborative study. Lancet 1998;351(9099):311-6.

3 Stalmans I, Lambrechts D, De Smet F, Jansen S, Wang J, Maity S, Kneer P, von der Ohe M, Swillen A, Maes C, Gewillig M, Molin DG, Hellings P, Boetel T, Haardt M, Compernolle V, Dewerchin M, Plaisance S, Vlietinck R, Emanuel B, Gittenberger-de Groot AC, Scambler P, Morrow B, Driscol DA, Moons L, Esguerra CV, Carmeliet G, Behn-Krappa A, Devriendt K, Collen D, Conway SJ, Carmeliet P. VEGF: a modifier of the del22q11 (DiGeorge) syndrome? Nat Med 2003;9(2):173-82.

4 Lambrechts D, Storkebaum E, Morimoto M, Del-Favero J, Desmet F, Marklund SL, Wyns S, Thijs V, Andersson J, van Marion I, Al-Chalabi A, Bornes S, Musson R, Hansen V, Beckman L, Adolfsson R, Pall HS, Prats H, Vermeire S, Rutgeerts P, Katayama S, Awata T, Leigh N, Lang-Lazdunski L, Dewerchin M, Shaw C, Moons L, Vlietinck R, Morrison KE, Robberecht W, Van Broeckhoven C, Collen D, Andersen PM, Carmeliet P. VEGF is a modifier of amyotrophic lateral sclerosis in mice and humans and protects motoneurons against ischemic death. Nat Genet 2003;34(4):383-94.

5 Kruglyak L, Daly MJ, Reeve-Daly MP, Lander ES. Parametric and nonparametric linkage analysis: a unified multipoint approach. Am J Hum Genet 1996;58(6):1347-63. 
6 Lohmueller KE, Pearce CL, Pike M, Lander ES, Hirschhorn JN. Meta-analysis of genetic association studies supports a contribution of common variants to susceptibility to common disease. Nat Genet 2003;33(2):177-82.

7 DerSimonian R, Laird N. Meta-analysis in clinical trials. Control Clin Trials 1986;7:177-88

8 Mantel N, Haenszel W. Statistical aspects of the analysis of data from retrospective studies of disease. J Natl Cancer Inst 1959;22:719-48.

9 Pradat P, Francannet C, Harris JA, Robert E. The epidemiology of cardiovascular defects, part I: a study based on data from three large registries of congenital malformations. Pediatr Cardiol 2003;24(3):195-221.

10 Jerome LA, Papaioannou VE. DiGeorge syndrome phenotype in mice mutant for the T-box gene, Tbx1. Nat Genet $2001 ; 27(3): 286-91$.

11 Lindsay EA, Vitelli F, Su H, Morishima M, Huynh T, Pramparo T, Jurecic V, Ogunrinu G, Sutherland HF, Scambler PJ, Bradley A, Baldini A. Tbx1 haploinsufficiency in the $\mathrm{DiGeorge}$ syndrome region causes aortic arch defects in mice. Nature 2001;410(6824):97-101.

12 Nora JJ, Berg K, Nora AH. Cardiovascular diseases (genetics, epidemiology and prevention). Oxford Monographs on Medical Genetics 1991;22.

13 Garg V, Kathiriya IS, Barnes R, Schluterman MK, King IN, Butler CA Rothrock CR, Eapen RS, Hirayama-Yamada K, Joo K, Matsuoka R, Cohen JC, Srivastava D. GATA4 mutations cause human congenital heart defects and reveal an interaction with TBX5. Nature 2003;424(6947):443-7.

14 Goldmuntz E, Geiger E, Benson DW. NKX2.5 mutations in patients with tetralogy of Fallot. Circulation 2001; 104(21):2565-8.

15 Yagi H, Furutani Y, Hamada H, Sasaki T, Asakawa S, Minoshima S, Ichida F, Joo K, Kimura M, Imamura S, Kamatani N, Momma K, Takao A,
Nakazawa M, Shimizu N, Matsuoka R. Role of TBX1 in human del22q11.2 syndrome. Lancet 2003;362(9393):1366-73.

16 Brennan P, Young ID. Congenital heart malformations: aetiology and associations. Semin Neonatol 2001;6(1):17-25.

17 Baldini A. DiGeorge syndrome: the use of model organisms to dissect complex genetics. Hum Mol Genet 2002;11(20):2363-9.

18 Dor Y, Djonov V, Abramovitch R, Itin A, Fishman GI, Carmeliet P, Goelman G, Keshet $\mathrm{E}$. Conditional switching of VEGF provides new insights into adult neovascularization and pro-angiogenic therapy. EMBO J 2002;21(8): 1939-47.

19 Miquerol L, Langille BL, Nagy A. Embryonic development is disrupted by modest increases in vascular endothelial growth factor gene expression. Development 2000;127(18):3941-6.

20 Carmeliet P, Ferreira V, Breier G, Pollefeyt S, Kieckens L, Gertsenstein M, Fahrig M, Vandenhoeck A, Harpal K, Eberhardt C, Declercq C, Pawling J, Moons L, Collen D, Risau W, Nagy A. Abnormal blood vessel development and lethality in embryos lacking a single VEGF allele. Nature 1996;380(6573):435-9

21 Ferrara N, Carver-Moore K, Chen H, Dowd M, Lu L, O'Shea KS, PowellBraxton L, Hillan KJ, Moore MW. Heterozygous embryonic lethality induced by targeted inactivation of the VEGF gene. Nature 1996;380(6573):439-42.

22 Storkebaum E, Carmeliet P. VEGF: a critical player in neurodegeneration. $J$ Clin Invest 2004;113(1):14-8.

23 Luttun A, Carmeliet P. Angiogenesis and lymphangiogenesis: highlights of the past year. Curr Opin Hematol 2004; 11(4):262-71

\section{Call for papers}

11 th European Forum on Quality Improvement in Health Care 26-28 April 2006, Prague, Czech Republic Deadline 30 September 2005.

For further information and to submit online go to: www.quality.bmipg.com 